\title{
Geographic Distribution of Fungicide-Insensitive Sclerotinia homoeocarpa Isolates from Golf Courses in the Northeastern United States
}

\author{
Alexander I. Putman, Former Graduate Research Assistant, Department of Plant Science, University of Connecti- \\ cut, Storrs 06269; Geunhwa Jung, Assistant Professor, Department of Plant, Soil, and Insect Sciences, University of \\ Massachusetts, Amherst 01003; and John E. Kaminski, Assistant Professor, Department of Crop and Soil Sciences, \\ The Pennsylvania State University, University Park 16802
}

\begin{abstract}
Putman, A. I., Jung, G., and Kaminski, J. E. 2010. Geographic distribution of fungicideinsensitive Sclerotinia homoeocarpa isolates from golf courses in the northeastern United States. Plant Dis. 94:186-195.

Chemical management of dollar spot in turf may lead to the development of Sclerotinia homoeocarpa populations with reduced fungicide sensitivity. The objective of this study was to determine the scope of $S$. homoeocarpa insensitivity to fungicides commonly used to control dollar spot on golf courses in the northeastern United States. A total of 965 and 387 isolates of S. homoeocarpa from intensively or individually sampled sites, respectively, were evaluated for in vitro sensitivity to iprodione, propiconazole, and thiophanate-methyl. Mean baseline sensitivities to iprodione and propiconazole were 0.2763 and $0.0016 \mu \mathrm{g}$ a.i. $\mathrm{ml}^{-1}$, respectively, and all baseline isolates were sensitive to thiophanate-methyl at $1,000 \mu \mathrm{g}$ a.i. $\mathrm{ml}^{-1}$. When compared with the baseline population, 14 and 18 of 20 total populations were less sensitive to iprodione and propiconazole, respectively. Individually sampled isolates obtained from fairways, putting greens, or tees were less sensitive to iprodione and propiconazole when compared with the baseline. For thiophanate-methyl, five populations were sensitive, six were resistant, and the remaining nine populations contained various proportions ( 2 to $92 \%$ ) of resistant isolates. Individually sampled isolates obtained from fairways and putting greens were evaluated for associations in sensitivity among the three fungicides. A weak but positive correlation in sensitivity to iprodione and propiconazole was observed for isolates resistant to thiophanate-methyl but correlations for sensitive isolates were not significant. Furthermore, isolates with highly reduced sensitivity to iprodione clustered in a narrow range of propiconazole sensitivity. These data suggest the possible existence of resistance mechanisms common to diverse fungicide classes. Overall, results indicate that insensitivity of $S$. homoeocarpa to iprodione, propiconazole, and thiophanate-methyl exists in varying degrees on golf courses in the northeastern United States.
\end{abstract}

Dollar spot, caused by the ascomycete fungus Sclerotinia homoeocarpa F.T. Bennett, is a disease that can cause severe damage to all grass species typically grown on golf courses in the United States $(33,35)$. Although cultural practices have been shown to reduce disease severity, chemical management of dollar spot is often necessary to suppress dollar spot to an acceptable threshold. In the northeastern United States, fungicides are typically applied from May through October. Repeated application of fungicides has been shown to induce the selection of $S$. homoeocarpa strains with reduced sensitivity to fungicides $(10,17,20,22$, 28,32). Populations of the pathogen with reduced sensitivity to specific active ingredients may compromise fungicide efficacy and limit the number of chemical

Corresponding author: J. E. Kaminski

E-mail: kaminski@psu.edu

Accepted for publication 1 October 2009.

doi:10.1094/PDIS-94-2-0186

(C) 2010 The American Phytopathological Society options available for controlling the disease.

Field resistance of $S$. homoeocarpa to early fungicides, including those containing heavy metals, was first observed in the late 1960 s $(8,27)$. Shortly after the introduction of the benzimidazoles, strains of $S$. homoeocarpa exhibiting in vitro resistance to benomyl and thiophanate-methyl were identified from golf courses in Illinois, New Jersey, Ohio, and Pennsylvania $(16,36)$. Two new classes of site-specific, penetrant compounds, the dicarboximides and the demethylation inhibitors (DMIs), became available for dollar spot control in the 1970s (1,17). Field resistance of $S$. homoeocarpa to the dicarboximides was first reported in Michigan in the early 1980s (10). Field resistance of S. homoeocarpa to the DMIs was first documented in Michigan in the early 1990s, more than 10 years after their introduction (34).

Since their respective first reports, $S$. homoeocarpa strains exhibiting resistance or reduced sensitivity to the aforementioned fungicide classes have been identified in Italy, Canada, and several states in the eastern United States, including Georgia, Indiana, Kentucky, Massachusetts,
Mississippi, North Carolina, Ohio, Tennessee, and Wisconsin $(3,6,10,11,20,21,23,25$, $28,29,32$ ). Despite the selection of less sensitive or resistant strains, these fungicides continue to be effectively utilized for dollar spot control in many locations.

Although field reports of reduced fungicide efficacy for dollar spot management are often attributed to pathogen resistance, various other factors, including cultural management practices, fungicide application techniques, and environmental conditions, likely affect fungicide efficacy. Variation in the chemical and cultural management regimes of golf course putting greens and fairways may also influence fungicide performance. It is possible that these regimes cause unique selection pressures that influence the development or persistence of field resistance. Koch et al. (25) reported that sensitivity of $S$. homoeocarpa to propiconazole and thiophanate-methyl varied among isolates obtained from fairways, putting greens, or roughs at seven golf courses in a narrow geographic region. Despite these results, the effect of various management regimes and the scope of insensitive $S$. homoeocarpa populations in the northeastern United States remain largely unknown. The objectives of this study were to (i) quantify the baseline sensitivity of a $S$. homoeocarpa population to iprodione, propiconazole, and thiophanate-methyl; (ii) determine the sensitivity of $S$. homoeocarpa isolates from golf courses in New England; and (iii) compare the sensitivities of $S$. homoeocarpa isolated from turf under various management regimes.

\section{MATERIALS AND METHODS}

Individually sampled isolates. Dollar spot samples were collected via site visits or samples received at the University of Connecticut Turfgrass Disease Diagnostic Lab in Storrs, CT from June 2006 to October 2007. For site visits, a small (2.5 to 10 cm by 2.5 to $10 \mathrm{~cm}$ by $7.5 \mathrm{~cm}$ deep) $\mathrm{sec}-$ tion of turf exhibiting dollar spot symptoms was removed, sealed in a plastic bag, and transported to the lab within $24 \mathrm{~h}$. All samples were placed in a Series 30 Controlled Environmental Chamber (Model I30BLLC8; Percival Scientific, Perry, IA) set to a 12-h light-and-dark cycle at approximately 24 and $13^{\circ} \mathrm{C}$, respectively $(2,12,31)$. 
Antibiotic water agar (AWA) was used for the initial isolation and was prepared by adding granulated agar (Difco Laboratories, Detroit) at $20 \mathrm{~g} \mathrm{liter}^{-1}$ of deionized water. Bottles containing 0.5 liter were stirred over heat for approximately $4 \mathrm{~min}$, autoclaved at $121^{\circ} \mathrm{C}$ for $25 \mathrm{~min}$, and then cooled to $50^{\circ} \mathrm{C}$. Penicillin-G potassium (Fisher Scientific, Fair Lawn, NJ) and streptomycin sulfate (Fisher Scientific) were added at $0.5 \mathrm{~g} \mathrm{liter}^{-1}$, and the molten media was stirred until the antibiotics dissolved. Molten AWA was poured into 100by-15-mm plastic petri plates (Fisher Scientific), allowed to cool overnight, and stored at $4^{\circ} \mathrm{C}$.

$S$. homoeocarpa was isolated from small $(\leq 5 \mathrm{~mm})$ sections of symptomatic leaf tissue within 1 week of collection. Most isolates were from annual bluegrass (Poa annua L.) or creeping bentgrass (Agrostis stolonifera L.) but a limited number of isolates were also obtained from colonial bentgrass (A. capillaris L.), Kentucky bluegrass (P. pratensis L.), perennial ryegrass (Lolium perenne L.), and roughstalk bluegrass ( $P$. trivialis L.). Symptomatic tissues were surface disinfested for $1 \mathrm{~min}$ in $0.5 \%$ sodium hypochlorite, washed three times for $30 \mathrm{~s}$ each in sterile deionized water, and air dried on sterile filter paper (Whatman Inc., Florham Park, NJ). Six pieces of tissue from each sample were placed on a single petri plate containing approximately $20 \mathrm{ml}$ of AWA. Plates containing disinfested tissues were sealed with Parafilm (Pechiney Plastic Packaging, Chicago) and incubated in the dark at $25 \pm$ $1^{\circ} \mathrm{C}$ for approximately 1 to 3 days.

Fast-growing, sparse colonies exhibiting aerial hyphal growth typical of $S$. homoeocarpa were identified, and 3-mm sections of media were removed from the edge of an actively growing colony and set onto fresh AWA. Cultures were incubated as previously described, and hyphae from the edge of an actively growing colony were transferred to petri plates containing potato dextrose agar (PDA) prepared by adding PDA (Difco Laboratories) at $39 \mathrm{~g} \mathrm{liter}^{-1}$ of deionized water. Except for the addition of antibiotic agents, preparation was similar to that of AWA. Cultures were identified by visual comparison of mature mycelial colonies to known isolates of $S$. homoeocarpa. Isolates were maintained by submerging 4-mm agar plugs from the edge of an actively growing colony in sealed plastic vials (Fisher Scientific) containing $1 \mathrm{ml}$ of sterile deionized water and stored at $4^{\circ} \mathrm{C}$.

Population sampling. Populations of $S$. homoeocarpa at selected golf courses were intensively sampled via site visits between 26 October and 16 November 2007. Samples were obtained within a $100-$ to $400-\mathrm{m}^{2}$ area of fairway or putting green turf or a $50-$ to $400-\mathrm{m}^{2}$ area from an individual tee. Sections $(\leq 5 \mathrm{~mm})$ of individual leaves exhibiting spots or bands with a bleached straw to white center and a tan to reddishbrown margin were removed and placed in $1.5-\mathrm{ml}$ polypropylene microcentrifuge tubes (Fisher Scientific). A single leaf was collected from each dollar spot infection center and sampled infection centers were separated by approximately $1 \mathrm{~m}$. In total, 48 to 95 symptomatic leaves were obtained per population. Except for one population that was immediately stored at $4^{\circ} \mathrm{C}$ for 24 $\mathrm{h}$, isolations were made on the day of collection.

Leaf tissue was disinfested by adding a $2 \%$ sodium hypochlorite solution to the microcentrifuge tubes and shaking vigorously for $15 \mathrm{~s}$. Tissues were then washed once in sterile deionized water for $1 \mathrm{~min}$ and air dried on sterile filter paper. Infected tissues were then set onto AWA as previously described, and active mycelia were transferred directly to PDA. Isolates

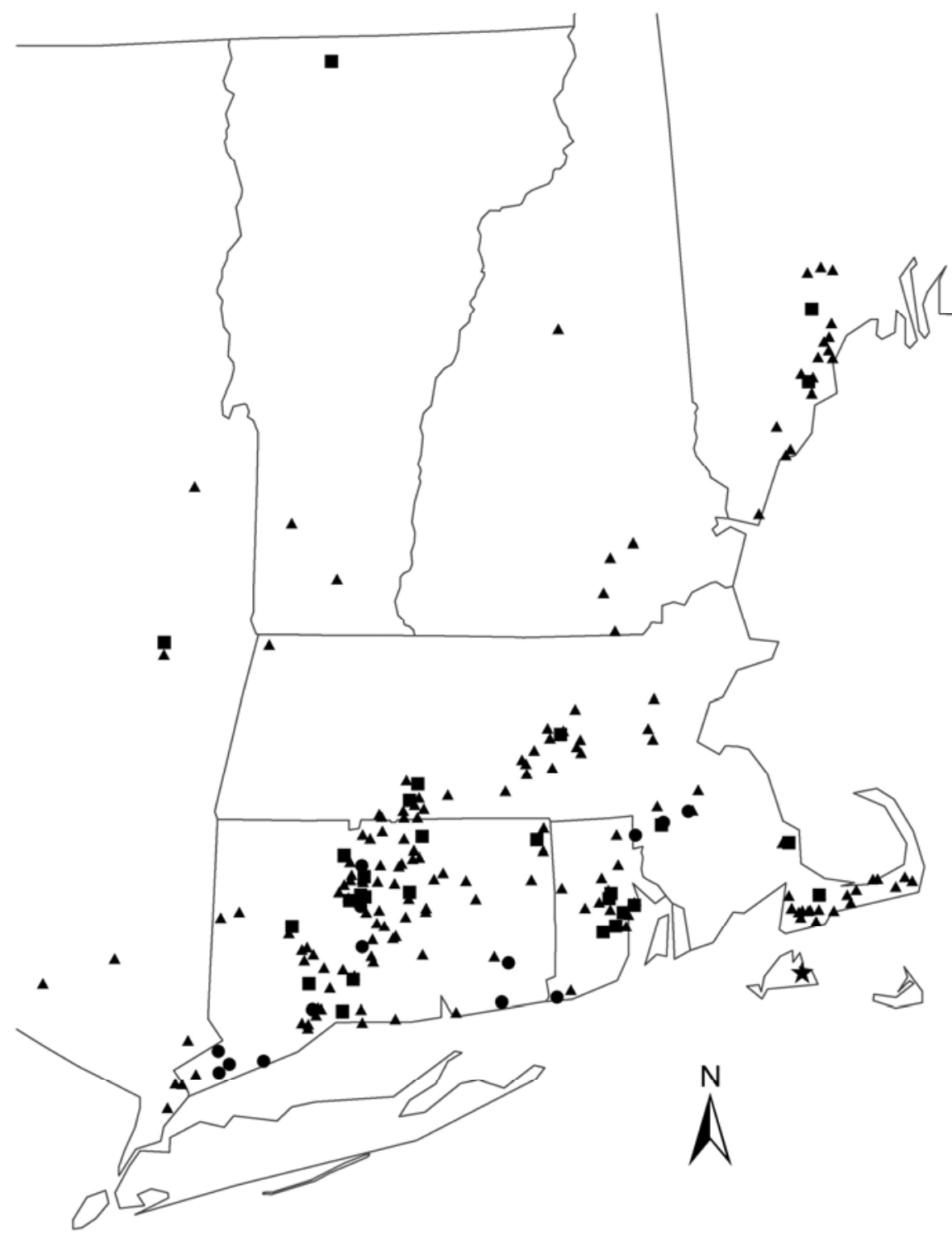

Fig. 1. Location of golf courses in New England and New York where Sclerotinia homoeocarpa isolates were obtained through intensive population $(\bullet ; n=909)$ or individual $(\boldsymbol{\Lambda} ; n=387)$ sampling. Golf courses contributing isolates used to determine the discriminatory dose $(\square ; n=31)$ are also presented. The unexposed baseline population $(\star ; n=56)$ was obtained from the Vineyard Golf Club in Edgartown, MA. were stored on PDA in a growth chamber at 18 or $25 \pm 1^{\circ} \mathrm{C}$ until needed. An isolate of $S$. homoeocarpa was retained for each successful isolation from individual leaves.

Twenty-two populations of $S$. homoeocarpa were sampled from fairways, putting greens, roughs, and tees of 18 golf courses in Connecticut, Massachusetts, and Rhode Island. In total, 1,104 isolates were obtained, and the number of isolates retained from a population ranged from 15 to 81 . Individually sampled isolates $(n=413)$ were obtained from 210 golf courses in all New England states and New York. Due to loss of several isolates, the intensively sampled isolates evaluated $(n=965)$ in this study originated from 21 populations on 17 golf courses (Fig. 1). Individually sampled isolates evaluated $(n=387)$ were obtained from 203 golf courses and the University of Connecticut (Fig. 1). 
Baseline in vitro sensitivity. The baseline sensitivity of a $S$. homoeocarpa population $(n=56)$ acquired from a putting green at the Vineyard Golf Club to iprodione and propiconazole was determined. The Vineyard Golf Club was constructed in 2002 in Edgartown, MA and had never been treated with synthetic pesticides. This unexposed $S$. homoeocarpa population served as the baseline for comparison to other isolates. The in vitro sensitivity assay was performed using fungicide-amended PDA. Liquid PDA was cooled to $50 \pm 1^{\circ} \mathrm{C}$ in an Isotemp Digital Control Water Bath (Model 215; Fisher Scientific) for 1 to $12 \mathrm{~h}$. Fungicide solutions were prepared by performing serial dilutions in sterile deionized water of commercial formulations of iprodione (Chipco 26GT; Bayer Crop Science, Kansas City, MO) or propiconazole (Banner MAXX, Syngenta Crop Protection, Greensboro, NC). Final fungicide concentrations were $0.1,0.4,0.7$, and $1.0 \mu \mathrm{g}$ a.i. $\mathrm{ml}^{-1}$ of PDA for iprodione and 0.0001, $0.001,0.01,0.1 \mu \mathrm{g}$ a.i. $\mathrm{ml}^{-1}$ of PDA for propiconazole. Fungicide-amended PDA was subjected to moderate stirring and then poured into petri plates at approximately $13 \pm 2 \mathrm{ml}$ of amended PDA per plate. Media were allowed to solidify at room temperature and stored at $4^{\circ} \mathrm{C}$.

Isolates were retrieved from storage and grown on fresh PDA prior to evaluation. After 2 to 5 days of incubation, 4-mmdiameter plugs were removed from the

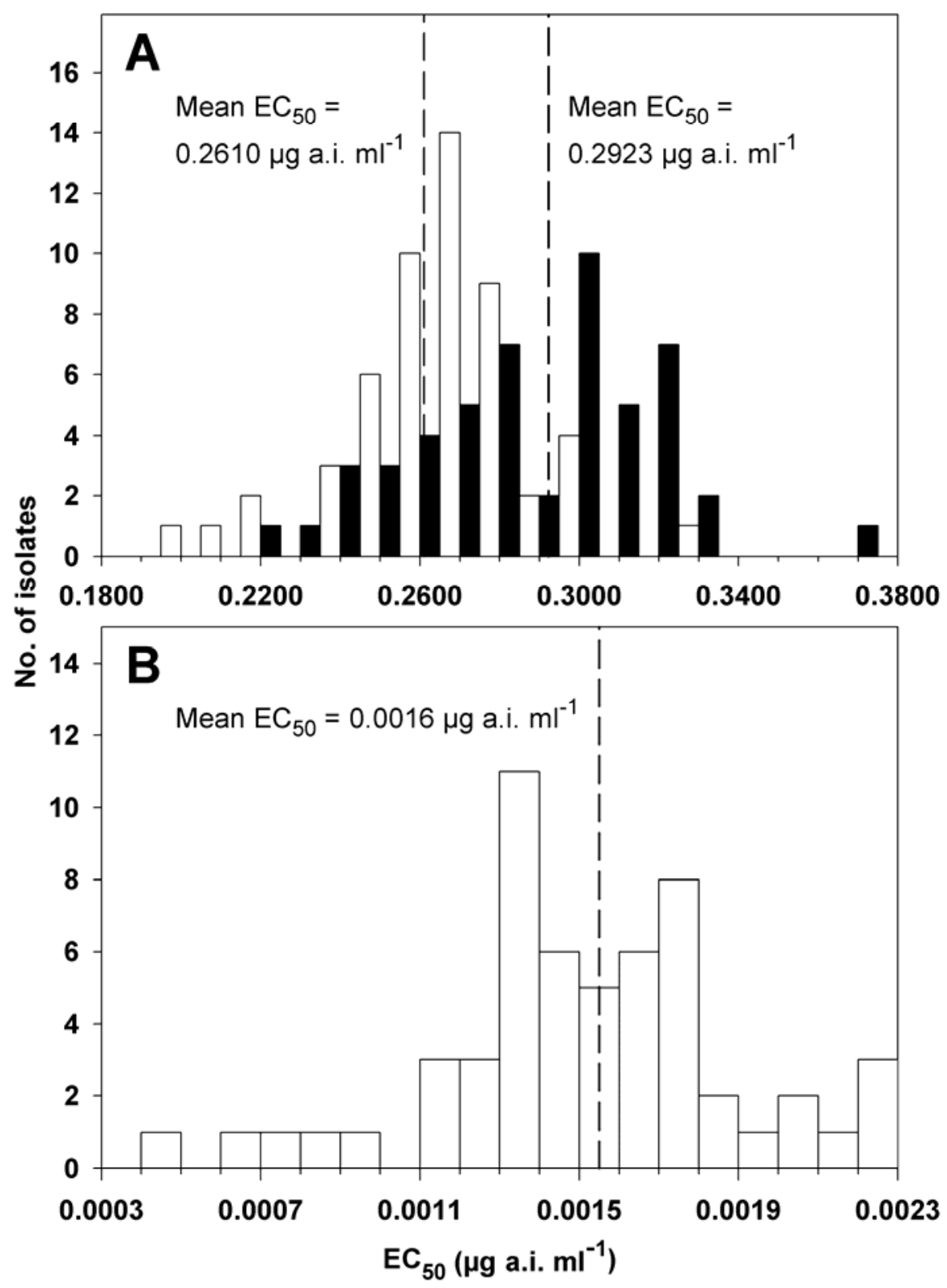

Fig. 2. Frequency distributions of fungicide concentration resulting in $50 \%$ growth inhibition $\left(\mathrm{EC}_{50}\right)$ to $\mathbf{A}$, iprodione and $\mathbf{B}$, propiconazole for Sclerotinia homoeocarpa isolates from an unexposed baseline population from the Vineyard Golf Club in Edgartown, MA as determined by growth on potato dextrose agar amended with four serial concentrations of fungicide. Sensitivity to iprodione was analyzed separately for each experimental run (hollow or filled bars). Dashed line represents the overall mean $\mathrm{EC}_{50}$ (propiconazole) and the mean of each run (iprodione). edge of an actively growing colony and set on fungicide-amended PDA. Nonamended PDA served as the nontreated control. Plates were sealed with Parafilm and incubated on a laboratory bench at room temperature $\left(25 \pm 5^{\circ} \mathrm{C}\right)$ under ambient light. Plates were arranged in a completely random design with two replications. The experiment was conducted twice.

Colony diameter was measured along two perpendicular lines after $48 \mathrm{~h}$, and total growth was adjusted by subtracting the diameter of the initial agar plug (4 $\mathrm{mm})$. The fungicide concentration resulting in $50 \%$ growth inhibition $\left(\mathrm{EC}_{50}\right)$ was modeled for each isolate using the PROBIT procedure (30). Colony diameter data were entered according to the MODEL statement (concentration $=$ amended diameter/control diameter). The mean diameter of both nonamended plates served as the control diameter. Fungicide concentration was $\log _{10}$ transformed prior to statistical analysis. Isolates exhibiting constrained growth or atypical colony morphology on nonamended PDA, which is consistent with the hypovirulent phenotype of S. homoeocarpa (37), were excluded from analyses.

Data were transformed into relative mycelial growth by dividing each colony diameter by the mean colony diameter on control plates for each respective experimental run. Diameters on amended media greater than the control diameter were considered equal to the control diameter for statistical analyses. The natural response rate $(c)$ utilized in the PROBIT procedure was calculated as follows: the mean control diameter was subtracted from each individual diameter, the absolute values of these differences were averaged, and the mean difference was divided by the mean of four control diameters for the respective experimental run. Values for each isolate were averaged to yield $c$ $(14,18,30)$.

Due to the qualitative nature of thiophanate-methyl sensitivity (23), isolates were grown on small (60-by-15-mm) plastic petri plates containing PDA amended with the active ingredient (3336; Cleary Chemical Corporation, Dayton, NJ) at $1,000 \mu \mathrm{g}$ a.i. $\mathrm{ml}^{-1}$. Plates were scored for the presence or absence of growth after approximately $48 \mathrm{~h}$.

Discriminatory concentration. To determine the discriminatory concentrations of iprodione and propiconazole to be used to screen all isolates, the sensitivity of a subset of isolates was determined as previously described for the baseline population from the Vineyard Golf Club. A random sample $(n=31)$ was selected from all individually sampled isolates $(n=413)$ to serve as a representative population of $S$. homoeocarpa from golf courses with a history of fungicide applications. Additionally, five isolates, which had been previously established as reference isolates 
based on in vitro sensitivity and fungicide performance in the field, were included to serve as sensitive and insensitive controls. The $\log _{10}$ of $\mathrm{EC}_{50}$ values was regressed against the mean relative growth value at each concentration of iprodione and propiconazole using the SAS Regression procedure. The concentration with the highest coefficient of determination $\left(r^{2}\right)$ for each fungicide was selected as the discriminatory concentration.

Sensitivity screening. Individually sampled isolates $(n=356)$ of $S$. homoeocarpa from New England and New York and 20 $S$. homoeocarpa populations $(n=909)$ from southern New England were evaluated for their sensitivity to iprodione, propiconazole, and thiophanate-methyl. The concentration used for each fungicide was selected based on the results of the discriminatory dose experiment. Media preparation and plate incubation were conducted as described previously. As described by Jo et al. (23), estimated $\mathrm{EC}_{50}$ values $\left(\mathrm{EC}_{50(\mathrm{D})}\right)$ were determined from relative growth values for iprodione and propiconazole using the regression equation from discriminatory dose analyses.

Statistical analyses. Relative mycelial growth values of $S$. homoeocarpa isolates were utilized for statistical analyses and population data were pooled into a single analysis. Population data were subjected to an analysis of variance using the SAS Mixed Model procedure, and means were separated with Tukey's honestly significant difference $(P \leq 0.05)$ test. Individually $(n=$ $387)$ or intensively sampled $(n=909)$ isolates were grouped by management loca-

Table 1. Sensitivity of intensively sampled populations of Sclerotinia homoeocarpa to thiophanate-methyl

\begin{tabular}{lcc}
\hline Population & No. evaluated $^{\mathbf{y}}$ & Resistant $^{(\%)^{\mathbf{z}}}$ \\
\hline VGC & 56 & 0 \\
CCC & 51 & 0 \\
FLD & 31 & 0 \\
FRM & 47 & 64 \\
NCN & 56 & 100 \\
HTR1 & 41 & 2 \\
HTR2 & 53 & 92 \\
LOI & 52 & 62 \\
OHP & 23 & 0 \\
OKL & 42 & 0 \\
PNO & 81 & 0 \\
SHN & 50 & 100 \\
STN & 42 & 55 \\
BOS1 & 41 & 100 \\
BOS2 & 42 & 100 \\
BOS3 & 15 & 47 \\
WCC & 52 & 31 \\
WEB & 55 & 100 \\
WPG1 & 57 & 100 \\
WPG2 & 22 & 32 \\
WHL & 56 & 86 \\
\hline
\end{tabular}

${ }^{\mathrm{y}}$ Number of $S$. homoeocarpa isolates from each population that were evaluated.

${ }^{z} S$. homoeocarpa was set on potato dextrose agar amended with thiophanate-methyl at $1,000 \mu \mathrm{g}$ a.i. $\mathrm{ml}^{-1}$ and scored for the presence or absence of growth after $48 \mathrm{~h}$ of incubation. tion (i.e., fairway, putting green, rough, and tee) and subjected to the previously described analysis of variance.

The influence of management location was evaluated by paired two-sample $t$ tests of mean isolate relative growth. Combination of experimental runs was determined to be appropriate and mean values for each isolate across all replications were obtained. In cases where multiple isolates were obtained from the same location on a course, these values were averaged. When isolates were obtained from multiple locations on the same course, the difference in relative growth for each location pair was calculated. The mean difference across all golf courses for a given location pair was obtained and tested against the null hypothesis that the mean difference $=0$ (i.e., management locations do not impact fungicide sensitivity) using Student's $t$ test in the Univariate procedure. The number of courses evaluated ranged from 11 to 60 .

Individually sampled $S$. homoeocarpa isolates from fairways and putting greens were evaluated for multiple resistance. The association between sensitivity to iprodione or propiconazole and thiophanate-methyl resistance was evaluated using analyses of variance on relative growth values. For each management location, separate analyses of variance were performed for iprodione and propiconazole that compared relative growth of isolates sensitive or resistant to thiophanate-methyl. In addition, any association between iprodione and propiconazole sensitivity of each isolate was evaluated using mean isolate relative growth values in the SAS Correlation procedure. Four separate correlation analyses were performed for isolates obtained from fairways or putting greens and sensitive or

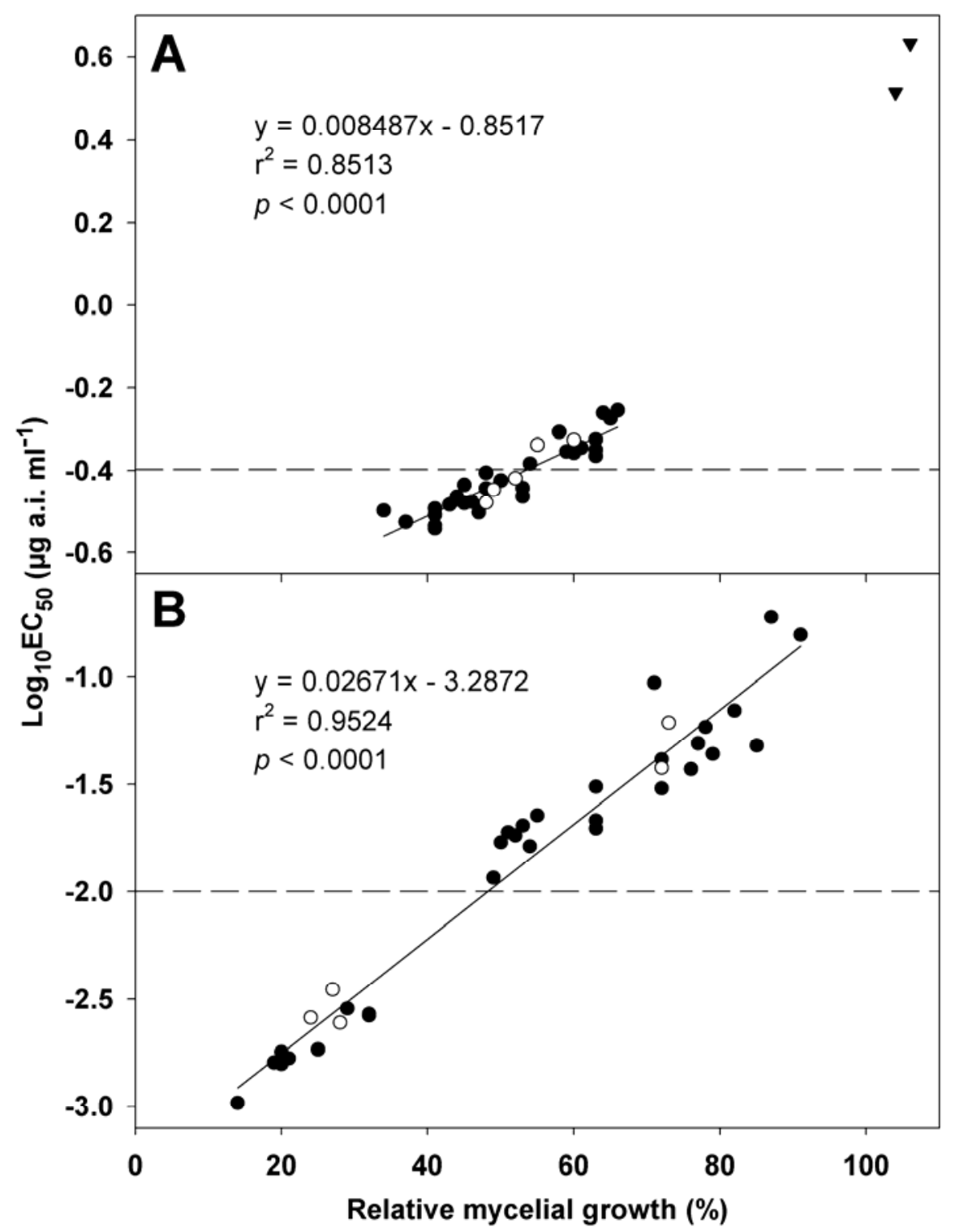

Fig. 3. Relationship between $\log _{10}$ fungicide concentration resulting in $50 \%$ growth inhibition $\left(\mathrm{EC}_{50}\right)$ values and relative mycelial growth of Sclerotinia homoeocarpa on potato dextrose agar amended with a discriminatory concentration (dashed line) of $\mathbf{A}$, iprodione $\left(0.4 \mu \mathrm{g}\right.$ a.i. $\left.\mathrm{ml}^{-1}\right)$ and $\mathbf{B}$, propiconazole $\left(0.01 \mu \mathrm{g}\right.$ a.i. $\left.\mathrm{ml}^{-1}\right) ; \bullet=S$. homoeocarpa isolates collected from 28 golf courses in New England, $\bigcirc=$ five reference isolates, and $\boldsymbol{\nabla}=$ two outlier isolates excluded from analysis for iprodione. 
resistant to thiophanate-methyl. These analyses were not performed for individually sampled isolates obtained from roughs or tees due to insufficient sample sizes.

\section{RESULTS}

Baseline sensitivity. The natural response rate $c$ was determined to be $2.2 \%$. probit analysis was performed separately on each run for iprodione and on both runs combined for propiconazole because the variances was rejected and retained, respectively. The mean and standard deviation of $\mathrm{EC}_{50}$ values for iprodione were $0.2923 \pm 0.0301$ and $0.2610 \pm 0.0224 \mu \mathrm{g}$ a.i. $\mathrm{ml}^{-1}$ for each run of baseline isolates, and $0.0016 \pm 0.0004 \mu \mathrm{g}$ a.i. $\mathrm{ml}^{-1}$ for propiconazole (Fig. 2). All baseline isolates were sensitive to thiophanate-methyl (Table 1).

Discriminatory concentration. Experimental runs were combined into a single analysis for iprodione and propiconazole to determine the discriminatory dose. The $\log _{10} \mathrm{EC}_{50}$ values were highly correlated with mean relative growth at the discriminatory concentrations of $0.4\left(r^{2}=\right.$ 0.8513; $P<0.0001)$ and $0.01 \mu \mathrm{g}$ a.i. $\mathrm{ml}^{-1}$ $\left(r^{2}=0.9524 ; P<0.0001\right)$ for iprodione and propiconazole, respectively (Fig. 3). Probit analysis estimated the $\mathrm{EC}_{50}$ values of iprodione for 2 of the 31 isolates to be 3.2764 and $4.2887 \mu \mathrm{g}$ a.i. $\mathrm{ml}^{-1}$. Because these concentrations were outside of the null hypothesis of equal experimental run

range of concentrations evaluated in this study, these isolates were excluded from analysis for iprodione.

Sensitivity screening. Relative growth values for each fungicide were transformed by ranking within each experimental run (9). In all, 6 of 20 populations from locations exposed to iprodione had mean relative growth values for iprodione (0.36 to $0.44)$ that were not significantly different from the mean of baseline isolates (0.38) (Table 2; Fig. 4). The remaining 14 populations were less sensitive to iprodione when compared with the baseline population, with mean relative growth values 35 to $124 \%$ higher than the baseline. Relative growth of the most-sensitive isolate of any exposed population was, at most, $10 \%$ greater than the least-sensitive isolate from the baseline population. In contrast to iprodione, reduced sensitivity to propiconazole was more prevalent and pronounced. In total, 18 of the 20 exposed populations had mean relative growth values that were 145 to $291 \%$ higher when compared with the mean $(0.21)$ of the baseline isolates (Table 2). Few differences were noted among 13 of the 18 lesssensitive populations containing isolates with relative growth values ranging from 0.21 to 0.90 . Isolates from the BOS 1 and SHN populations were the least sensitive to propiconazole when compared with 14 of the 16 remaining less-sensitive populations.

Table 2. Relative mycelial growth of intensively sampled populations of Sclerotinia homoeocarpa from New England on potato dextrose agar (PDA) amended with a discriminatory concentration of iprodione or propiconazole

\begin{tabular}{|c|c|c|c|c|c|}
\hline \multirow[b]{3}{*}{ Population } & \multirow[b]{3}{*}{ No..$^{y}$} & \multicolumn{4}{|c|}{ Relative growth $^{x}$} \\
\hline & & \multicolumn{2}{|c|}{ Iprodione } & \multicolumn{2}{|c|}{ Propiconazole } \\
\hline & & Mean & Range & Mean & Range \\
\hline $\mathrm{VGC}^{\mathrm{z}}$ & 56 & $0.38 \mathrm{i}$ & $0.20-0.50$ & $0.21 \mathrm{i}$ & $0.08-0.29$ \\
\hline $\mathrm{CCC}$ & 51 & 0.43 ghi & $0.30-0.61$ & $0.36 \mathrm{i}$ & $0.20-0.67$ \\
\hline FLD & 31 & 0.54 efg & $0.25-0.95$ & 0.61 efg & $0.36-0.87$ \\
\hline FRM & 47 & $0.60 \mathrm{~b}-\mathrm{e}$ & $0.38-0.79$ & $0.75 \mathrm{bc}$ & $0.43-0.98$ \\
\hline $\mathrm{NCN}$ & 56 & $0.58 \mathrm{~b}-\mathrm{e}$ & $0.52-0.75$ & $0.80 \mathrm{ab}$ & $0.55-0.91$ \\
\hline HTR1 & 41 & $0.76 a b c$ & $0.54-1.05$ & $0.55 \mathrm{gh}$ & $0.32-0.64$ \\
\hline HTR2 & 53 & $0.65 a b c$ & $0.53-0.72$ & $0.54 \mathrm{~h}$ & $0.48-0.61$ \\
\hline LOI & 52 & $0.56 \mathrm{de}$ & $0.41-0.65$ & 0.60 efg & $0.29-0.82$ \\
\hline OHP & 23 & $0.41 \mathrm{hi}$ & $0.28-0.50$ & $0.58 \mathrm{fgh}$ & $0.42-0.74$ \\
\hline OKL & 42 & $0.36 \mathrm{i}$ & $0.21-0.61$ & $0.62 \mathrm{def}$ & $0.38-0.82$ \\
\hline PNO & 81 & 0.43 ghi & $0.30-0.53$ & 0.61 efg & $0.48-0.74$ \\
\hline SHN & 50 & $0.62 \mathrm{bcd}$ & $0.52-0.83$ & $0.85 \mathrm{a}$ & $0.70-0.97$ \\
\hline STN & 42 & $0.57 \mathrm{cde}$ & $0.43-0.66$ & 0.60 efg & $0.24-0.79$ \\
\hline BOS1 & 41 & $0.67 \mathrm{ab}$ & $0.55-0.72$ & $0.86 \mathrm{a}$ & $0.77-0.99$ \\
\hline BOS2 & 42 & $0.63 \mathrm{a}-\mathrm{d}$ & $0.36-0.82$ & $0.83 \mathrm{ab}$ & $0.65-0.95$ \\
\hline BOS3 & 15 & $0.54 \mathrm{def}$ & $0.38-0.66$ & 0.55 efg & $0.21-0.90$ \\
\hline WCC & 52 & $0.50 \mathrm{e}-\mathrm{h}$ & $0.34-0.73$ & $0.63 \mathrm{ef}$ & $0.43-0.90$ \\
\hline WEB & 55 & $0.44 \mathrm{f}-\mathrm{i}$ & $0.34-0.62$ & $0.65 \mathrm{de}$ & $0.56-0.85$ \\
\hline WPG1 & 57 & $0.83 \mathrm{a}$ & $0.49-1.00$ & $0.56 \mathrm{fgh}$ & $0.31-0.80$ \\
\hline WPG2 & 22 & $0.44 \mathrm{f}-\mathrm{i}$ & $0.34-0.55$ & $0.26 \mathrm{i}^{\circ}$ & $0.14-0.38$ \\
\hline WHL & 56 & $0.55 \mathrm{de}$ & $0.42-0.64$ & $0.69 \mathrm{~cd}$ & $0.52-0.84$ \\
\hline
\end{tabular}

${ }^{x}$ Relative mycelial growth was calculated after $48 \mathrm{~h}$ by dividing the mean colony diameter of $S$. homoeocarpa on PDA amended with iprodione $(0.4 \mu \mathrm{g}$ a.i. ml-1 $)$ or propiconazole $\left(0.01 \mu \mathrm{g}\right.$ a.i. $\left.\mathrm{ml}^{-1}\right)$ by the mean diameter of isolates grown on non-amended PDA. Within a fungicide, means followed by the same letter are not significantly different according to Tukey's honestly significant difference test at $P \leq 0.05$. Data were rank-transformed prior to analysis, but actual means are shown.

${ }^{y}$ Number of $S$. homoeocarpa isolates from each population that were evaluated.

${ }^{\mathrm{z}}$ VGC represents baseline isolates of $S$. homoeocarpa that were collected from a golf course putting green with no history of fungicide use.
Among populations, wide variation in sensitivity to thiophanate-methyl was observed. In addition to the baseline, $100 \%$ of isolates from five populations were sensitive to thiophanate-methyl (Table 1). Population HTR1 $(n=41)$ contained a single resistant isolate, and nine populations contained 31 to $92 \%$ resistant isolates.

Mean relative growth values of individually sampled isolates obtained from golf course roughs were not significantly different from relative growth values of isolates from the baseline population for iprodione and propiconazole (Table 3). Mean relative growth of isolates from fairways, putting greens, and tees were significantly higher when compared with the baseline population. The least-sensitive isolate from these locations had relative growth values approximately two or three times that of the least-sensitive baseline isolate for iprodione and propiconazole, respectively.

Although $45 \%$ of all individually sampled isolates evaluated were resistant to thiophanate-methyl, resistant isolates were found approximately five times more frequently in fairways and nearly seven times more frequently in putting greens or tees when compared with isolates obtained from roughs (Table 4). The proportions of resistant isolates obtained from fairways and putting greens were similar across both sampling strategies. However, resistant isolates obtained from tees were found less frequently in individual sampling when compared with the two intensively sampled populations from tees.

Populations WPG1 and WPG2 were obtained from a putting green and fairway, respectively, on the same golf course. Mean relative growth values of WPG1 isolates were approximately twice those from WPG2 for both iprodione and propiconazole (Table 2). In contrast to WPG, mean relative growth values between putting green and fairway populations at site HTR did not significantly differ for either fungicide. However, the fairway population (HTR1) contained isolates with nearly the highest relative growth values on iprodione (1.05) observed in this study. At location BOS, mean relative growth values between the fairway (BOS1) and tee (BOS2) populations did not significantly differ for iprodione and propiconazole. When compared with the rough population (BOS3), however, mean relative growth values for propiconazole of BOS1 and BOS2 were 56 and $51 \%$ higher, respectively.

When individually sampled isolates obtained from different locations on the same course were compared, relative growth values for propiconazole of isolates obtained from fairways, putting greens, and tees were 133,144 , and $187 \%$ higher on average, respectively, and significantly different when compared with the isolates 
from the rough (Table 5). Isolates obtained from putting greens had relative growth values for propiconazole that were, on average, greater by 0.12 when compared with paired isolates from fairways. For iprodione, differences were smaller and only significant between isolates collected from fairways or tees and those from the rough.

Individually sampled isolates resistant to thiophanate-methyl were less sensitive to propiconazole when compared with isolates sensitive to thiophanate-methyl. Mean relative growth on propiconazoleamended PDA for isolates resistant to thiophanate-methyl was 71 and $43 \%$ higher for isolates obtained from fairways and putting greens, respectively, when compared with isolates sensitive to thiophanate-methyl (Table 6). Mean relative growth for iprodione was $8 \%$ higher for isolates obtained from putting greens that were resistant to thiophanate-methyl when compared with sensitive isolates from greens. Although isolates obtained from fairways and resistant to thiophanatemethyl were less sensitive to iprodione when compared with sensitive isolates from fairways, this difference was small and not significant $(P=0.0587)$.

Relative growth values for iprodione and propiconazole were correlated $(P=0.0008$ to 0.0137$)$ for isolates resistant to thiophanate-methyl regardless of turf management location (Fig. 5). For isolates resistant to thiophanate-methyl, the coefficients of determination revealed that approximately $12 \%$ of the variation in relative growth values between the two fungicides was associated. No correlation between iprodione and propiconazole was observed among isolates sensitive to thiophanate-methyl, regardless of location. Despite these trends in correlation, isolates exhibiting highly reduced sensitivity to iprodione $(0.97 \leq$ relative growth $\leq 1.06)$ appeared to cluster in a narrow range of propiconazole sensitivity $(0.49 \leq$ relative growth $\leq 0.61$, regardless of location or thiophanate-methyl sensitivity.

\section{DISCUSSION}

In New England, management of dollar spot has become increasingly difficult in recent years. The presence of $S$. homoeocarpa with reduced fungicide sensitivity suggests that resistance may contribute to the challenges of dollar spot management, but the cause of the recent intensification in dollar spot remains unclear due to the lack of previous sensitivity monitoring in New England. In a few select cases, however, this study confirmed that resistance to iprodione, propiconazole, or thiophanatemethyl likely contributed to poor disease control following fungicide application.

The mean baseline sensitivity to iprodione $\left(0.2763 \mu \mathrm{g}\right.$ a.i. $\left.\mathrm{ml}^{-1}\right)$ from an unexposed baseline population at the Vine-

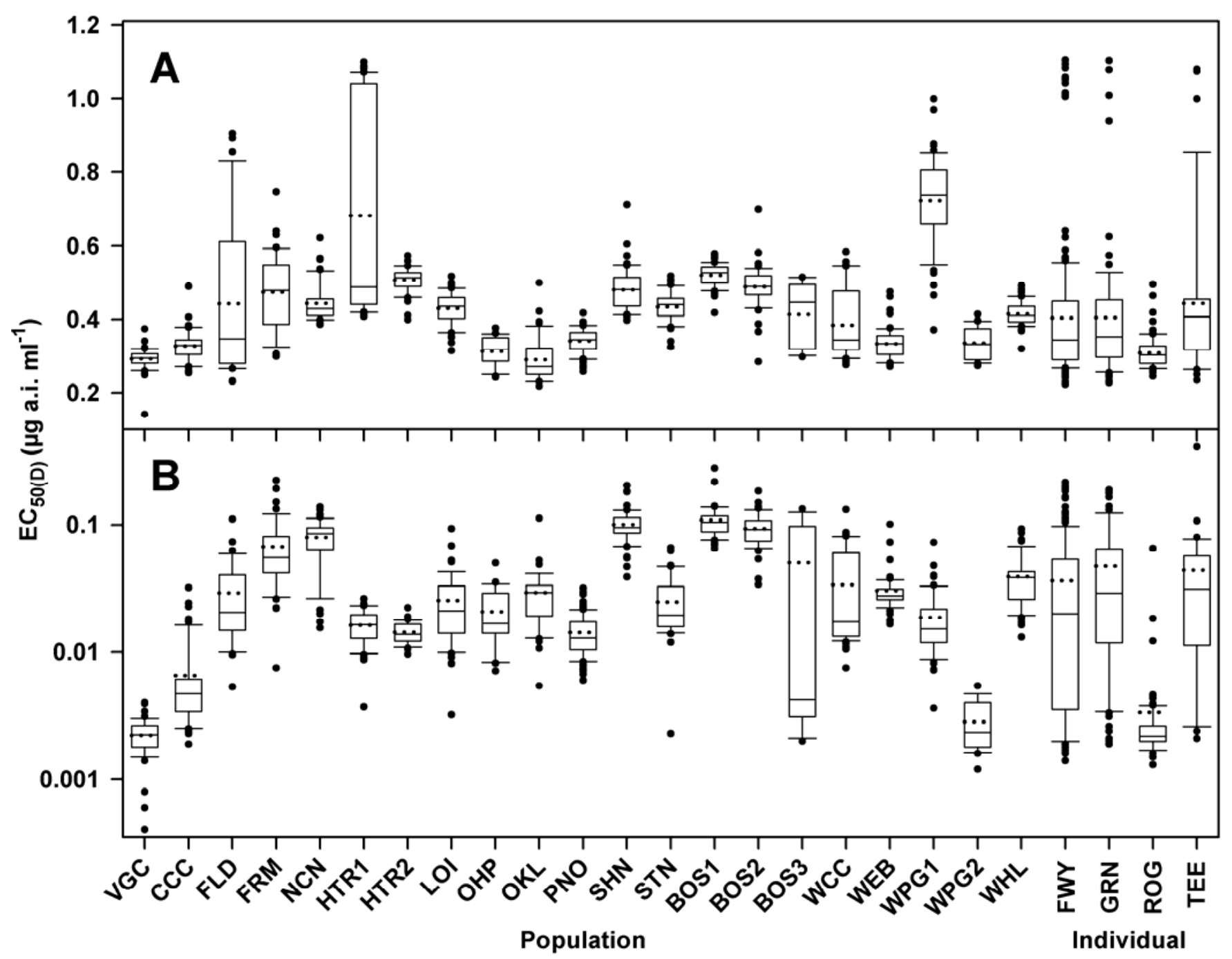

Fig. 4. Sensitivity distributions of Sclerotinia homoeocarpa isolates from intensively sampled populations $(n=965)$ or individually sampled isolates $(n=$ 387) from putting greens, tees, fairways, and roughs in New England using the estimated fungicide concentration resulting in $50 \%$ growth inhibition $\left(\mathrm{EC}_{50(\mathrm{D})}\right)$ obtained by growth on potato dextrose agar amended with a discriminatory concentration of A, iprodione $\left(0.4 \mu \mathrm{g}\right.$ a.i. $\left.\mathrm{ml}^{-1}\right)$ or $\mathbf{B}$, propiconazole $\left(0.01 \mu \mathrm{g}\right.$ a.i. $\left.\mathrm{ml}^{-1}\right)$. Lower and upper bounds of the box represent the 25 th and 75 th percentiles, respectively, and lower and upper whiskers denote the 10th and 90th percentiles, respectively. The median $\mathrm{EC}_{50(\mathrm{D})}$ value (solid line), mean (dotted line), and outlier isolates (•) are also presented. VGC is an unexposed baseline population from Edgartown, MA. Individually sampled isolates were grouped by management location: FWY = fairway, GRN $=$ putting green, $\mathrm{ROG}=$ rough , and $\mathrm{TEE}=$ tee . 
yard Golf Club was higher when compared with the sensitivity $\left(0.15 \mu \mathrm{g}\right.$ a.i. $\left.\mathrm{ml}^{-1}\right)$ of a baseline population in Ohio (23). Although the range of isolate sensitivities in Ohio was wide $\left( \pm 0.08 \mu\right.$ g a.i. $\left.\mathrm{ml}^{-1}\right)$, the higher mean $\mathrm{EC}_{50}$ and relatively low variability $( \pm$ $0.0246 \mu \mathrm{g}$ a.i. $\mathrm{ml}^{-1}$ ) found in this study suggest the possibility of reduced iprodione sensitivity of $S$. homoeocarpa at the Vineyard Golf Club. However, individually sampled isolates obtained from roughs on 90 golf courses in New England did not differ in relative growth on the discriminatory concentration of iprodione when considered as a group and compared with relative growth values of baseline isolates (Table 3). Data from this study suggest that the baseline population represents the natural sensitivity of $S$. homoeocarpa to iprodione in New England.

The mean $\mathrm{EC}_{50}$ for propiconazole of baseline isolates $\left(0.0016 \mu \mathrm{g}\right.$ a.i. $\left.\mathrm{ml}^{-1}\right)$ was similar to that of other unexposed populations $\left(0.002\right.$ to $0.009 \mu \mathrm{g}$ a.i. $\left.\mathrm{ml}^{-1}\right)$ from Georgia, Michigan, Ohio, and Ontario $(17,21,23,28)$. As for iprodione, similar

Table 3. Relative mycelial growth of Sclerotinia homoeocarpa isolates grown on potato dextrose agar (PDA) amended with iprodione or propiconazole

\begin{tabular}{|c|c|c|c|c|}
\hline \multirow[b]{2}{*}{ Sampling, fungicide ${ }^{y}$} & \multirow[b]{2}{*}{ Location $^{\mathrm{z}}$} & \multirow[b]{2}{*}{ No. evaluated } & \multicolumn{2}{|c|}{ Relative growth $^{x}$} \\
\hline & & & Mean & Range \\
\hline \multicolumn{5}{|l|}{ Individual } \\
\hline \multirow[t]{6}{*}{ Iprodione } & VGC & 56 & $0.38 \mathrm{~b}$ & $0.20-0.50$ \\
\hline & Fairway & 178 & $0.50 \mathrm{a}$ & $0.23-1.06$ \\
\hline & Green & 73 & $0.51 \mathrm{a}$ & $0.25-1.05$ \\
\hline & Rough & 90 & $0.40 \mathrm{~b}$ & $0.28-0.64$ \\
\hline & Tee & 36 & $0.55 \mathrm{a}$ & $0.26-1.05$ \\
\hline & Unknown & 10 & $0.52 \mathrm{a}$ & $0.32-1.02$ \\
\hline \multirow[t]{6}{*}{ Propiconazole } & VGC & 56 & $0.21 \mathrm{~b}$ & $0.08-0.29$ \\
\hline & Fairway & 178 & $0.56 \mathrm{a}$ & $0.16-0.96$ \\
\hline & Green & 73 & $0.63 \mathrm{a}$ & $0.21-0.94$ \\
\hline & Rough & 90 & $0.25 \mathrm{~b}$ & $0.14-0.79$ \\
\hline & Tee & 36 & $0.61 \mathrm{a}$ & $0.22-1.02$ \\
\hline & Unknown & 10 & $0.63 \mathrm{a}$ & $0.21-0.75$ \\
\hline \multicolumn{5}{|l|}{ Population } \\
\hline \multirow[t]{5}{*}{ Iprodione } & VGC & 56 & $0.38 \mathrm{c}$ & $0.20-0.50$ \\
\hline & Fairway & 555 & $0.53 \mathrm{~b}$ & $0.21-1.05$ \\
\hline & Green & 241 & $0.61 \mathrm{a}$ & $0.30-1.00$ \\
\hline & Rough & 15 & $0.54 \mathrm{~b}$ & $0.38-0.66$ \\
\hline & Tee & 98 & $0.60 \mathrm{a}$ & $0.36-0.82$ \\
\hline \multirow{5}{*}{ Propiconazole } & VGC & 56 & $0.21 \mathrm{c}$ & $0.08-0.29$ \\
\hline & Fairway & 555 & $0.61 \mathrm{~b}$ & $0.14-0.99$ \\
\hline & Green & 241 & $0.63 \mathrm{~b}$ & $0.31-0.97$ \\
\hline & Rough & 15 & $0.55 \mathrm{~b}$ & $0.21-0.90$ \\
\hline & Tee & 98 & $0.81 \mathrm{a}$ & $0.55-0.95$ \\
\hline
\end{tabular}

$\bar{x}$ Relative mycelial growth was calculated after $48 \mathrm{~h}$ by dividing the mean colony diameter of $S$. homoeocarpa grown on PDA amended with iprodione $\left(0.4 \mu \mathrm{g}\right.$ a.i. $\left.\mathrm{ml}^{-1}\right)$ or propiconazole $(0.01 \mu \mathrm{g}$ a.i. $\mathrm{ml}^{-1}$ ) by the mean diameter of isolates grown on non-amended PDA. Within each sampling method and fungicide, means followed by the same letter are not significantly different according to Tukey's honestly significant difference test at $P \leq 0.05$. Data were rank-transformed prior to analysis, but actual means are shown.

${ }^{y}$ Individually sampled isolates $(n=387)$ were obtained from 204 locations, whereas population isolates $(n=909)$ comprised representative samples of 20 populations from 16 golf courses.

${ }^{z}$ VGC represents baseline isolates of $S$. homoeocarpa that were collected from a golf course putting green with no history of fungicide use. Unknown $=$ isolates for which the originating management location is unclear.

Table 4. Resistance to thiophanate-methyl of Sclerotinia homoeocarpa isolated from various golf course management locations

\begin{tabular}{lccccc}
\hline & \multicolumn{4}{c}{ Sampling } \\
\cline { 2 - 3 } & \multicolumn{2}{c}{ Individual } & & \multicolumn{2}{c}{ Population } \\
\cline { 2 - 3 } \cline { 5 - 6 } Location $^{\mathbf{y}}$ & No. evaluated & Resistant $(\boldsymbol{\%})^{\mathbf{z}}$ & & No. evaluated & Resistant (\%) \\
\hline VGC & $\ldots$ & $\ldots$ & & 56 & 0 \\
Fairway & 178 & 50 & & 555 & 46 \\
Green & 73 & 66 & & 241 & 65 \\
Rough & 90 & 10 & & 15 & 47 \\
Tee & 36 & 67 & & 98 & 100 \\
Unknown & 10 & 60 & & $\ldots$ & $\ldots$ \\
\hline
\end{tabular}

${ }^{\mathrm{y}}$ Isolates obtained through intensive population or individual sampling were grouped according to the originating management location. VGC represents baseline isolates of $S$. homoeocarpa that were collected from a golf course putting green with no history of fungicide use. Unknown = isolates for which the originating management location is unclear.

${ }^{\mathrm{z}} \mathrm{S}$. homoeocarpa was set on potato dextrose agar amended with thiophanate-methyl at 1,000 $\mu \mathrm{g}$ a.i. $\mathrm{ml}^{-1}$ and scored for the presence or absence of growth after $48 \mathrm{~h}$ of incubation. relative growth values for propiconazole between individually sampled isolates from roughs and baseline isolates (Table 3) suggests that $S$. homoeocarpa populations within these locations have experienced little to no selection toward reduced sensitivity. In addition, sensitivity of baseline isolates was similar to that of unexposed populations as reported by Koch et al. (25) by comparison of relative growth on PDA amended with propiconazole at $0.1 \mu \mathrm{g}$ a.i. $\mathrm{ml}^{-1}$ (data not shown). The lack of isolates in the baseline sample resistant to thiophanate-methyl is consistent with the baseline population from Ohio (23). Previous research, however, has identified a low proportion of thiophanate-methyl-resistant isolates from populations believed to be unexposed $(25,32)$.

Discrepancies in the baseline sensitivity to iprodione and discriminatory dose concentrations for iprodione and propiconazole may have arisen from the different methods used to determine $\mathrm{EC}_{50}$. Whereas Jo et al. (23) used linear regression, $\mathrm{EC}_{50}$ was determined in the present study by the probit transformation. The probit equation is a sigmoidal, decreasing function that was developed for use in toxicology research (4). The equation more accurately models the "diminishing returns" effect of a toxicant at extreme concentrations while accounting for the linear response at concentrations close to the $\mathrm{EC}_{50}$ and, thus, is well suited for regression of quantitative biological responses to toxic substances (15). The probit transformation has been used previously in $S$. homoeocarpa sensitivity assays $(3,20,21,28)$.

Sensitivity to iprodione appeared to be quantitatively distributed based on select isolates tested in the in vitro analysis after two isolates with highly reduced sensitivity were excluded as outliers. However, the discrete sensitivity distribution of all individually sampled isolates, including the outliers obtained from fairways, putting greens, or tees, suggests that sensitivity of $S$. homoeocarpa to the dicarboximides is qualitatively inherited. Although possibly governed by both a qualitative and quantitative mechanism, reduced sensitivity to dicarboximide fungicides is generally understood to be predominately under the control of a single locus as reported in Botryotinia fuckeliana (de Bary) Whetzel (13). The low degree of reduced sensitivity and low incidence of isolates with highly reduced sensitivity found in the present study suggest that reduced sensitivity to iprodione in $S$. homoeocarpa is not common in New England. Similar results in other studies on $S$. homoeocarpa $(23,32)$ imply that, despite frequent use of dicarboximide fungicides for dollar spot control, factors such as fitness costs or very low mutation rates may account for the infrequent appearance of reduced sensitivity to dicarboximides in the United States. The fitness of $S$. homoeocarpa with re- 
duced dicarboximide sensitivity and the relationship between in vitro sensitivity and dollar spot control remains poorly understood.

In contrast to iprodione, reduced sensitivity to propiconazole was more severe and more prevalent among populations and individually sampled isolates. The level of reduced sensitivity of exposed isolates in this study agrees with values reported previously $(17,20,23,28)$. Population SHN was sampled from a golf course where failure of DMI fungicides had been experienced. The mean $\mathrm{EC}_{50(\mathrm{D})}$ of isolates from SHN $\left(0.1004 \mu \mathrm{g}\right.$ a.i. $\left.\mathrm{ml}^{-1}\right)$ is very similar to the mean sensitivity $\left(0.103 \mu \mathrm{g}\right.$ a.i. $\left.\mathrm{ml}^{-1}\right)$ of $S$. homoeocarpa isolates from three golf courses in Michigan where DMI control failures were first reported (17). In contrast, no specific DMI control failures were reported at locations that contained a population of $S$. homoeocarpa with mean $\mathrm{EC}_{50(\mathrm{D})}$ values similar to SHN.

Table 5. Comparison of relative mycelial growth on potato dextrose agar (PDA) amended with a discriminatory concentration of iprodione or propiconazole of individually sampled Sclerotinia homoeocarpa isolates from different management locations when paired by golf course

\begin{tabular}{lllllr}
\hline Fungicide, location & Mean $^{\mathbf{x}}$ & Location & Mean & No. $^{\mathbf{y}}$ & $\boldsymbol{P ~ v a l u e}^{\mathbf{z}}$ \\
\hline Iprodione & & & & & \\
Fairway & 0.52 & Green & 0.52 & 45 & 0.9876 \\
& 0.50 & Tee & 0.57 & 22 & 0.2884 \\
& 0.52 & Rough & 0.40 & 60 & $<0.0001$ \\
Green & 0.50 & Tee & 0.55 & 11 & 0.4481 \\
& 0.51 & Rough & 0.41 & 19 & 0.0541 \\
Tee & 0.53 & Rough & 0.40 & 13 & 0.0421 \\
Propiconazole & & & & & \\
Fairway & 0.51 & Green & 0.63 & 45 & 0.0029 \\
& 0.58 & Tee & 0.64 & 22 & 0.2972 \\
& 0.55 & Rough & 0.25 & 60 & $<0.0001$ \\
Green & 0.63 & Tee & 0.64 & 11 & 0.9606 \\
& 0.60 & Rough & 0.26 & 19 & $<0.0001$ \\
Tee & 0.68 & Rough & 0.24 & 13 & $<0.0001$ \\
\hline
\end{tabular}

${ }^{x}$ Mean relative mycelial growth represents only isolates from a given comparison of management locations. Relative mycelial growth was calculated after $48 \mathrm{~h}$ by dividing the mean colony diameter of $S$. homoeocarpa grown on PDA amended with iprodione $\left(0.4 \mu \mathrm{g}\right.$ a.i. $\left.\mathrm{ml}^{-1}\right)$ or propiconazole $(0.01$ $\mu \mathrm{g}$ a.i. $\mathrm{ml}^{-1}$ ) by the mean diameter of isolates grown on non-amended PDA.

${ }^{y}$ Number of courses from which isolates were obtained from both locations in the given comparison.

${ }^{\mathrm{z}}$ Influence of management location on fungicide sensitivity was evaluated for each location comparison by performing a Student's paired $t$ test on differences in relative growth between isolates paired by golf course.
The management location from which an isolate was obtained appeared to be associated with the observed sensitivity to iprodione, propiconazole, and thiophanatemethyl. The observation of differences in iprodione sensitivities between fairways and putting greens at sites HTR and WPG and the lack of differences when individually sampled isolates were paired suggest that strong differences in dicarboximide selection pressures between these locations are uncommon. Another possibility is that the fitness cost associated with reduced dicarboximide sensitivity may have masked any influence of differing selection pressures. For propiconazole, analysis of paired individually sampled isolates suggests that reduced sensitivity of $S$. homoeocarpa may be more common on putting greens than on fairways. This result for propiconazole agrees with that of Koch et al. (25). Putting greens require increased fungicide inputs due to particularly low disease thresholds when compared with fairways. Thus, greater use of propiconazole and other DMI fungicides likely causes a stronger pressure for selection of $S$. homoeocarpa with reduced sensitivity. However, research is lacking on the myriad factors influencing resistance development in S. homoeocarpa.

The different sampling strategies employed in this study yielded similar results for all three fungicides. The sensitivity of isolates obtained from intensively sampled populations grouped by management location was generally similar to that of individually sampled isolates from fairways and putting greens, suggesting that an individual sample from a sufficient number of locations may collectively represent $S$. homoeocarpa sensitivity in a given geographic region. However, the reduced sensitivity to propiconazole and thiophanatemethyl of the two golf tee populations (BOS2 and NCN) when compared with the group of individually sampled isolates from tees suggests that these populations are not representative of $S$. homoeocarpa

Table 6. Association of thiophanate-methyl resistance with either iprodione or propiconazole sensitivity as measured by the relative mycelial growth of individually sampled Sclerotinia homoeocarpa on potato dextrose agar (PDA) amended with discriminatory concentrations of these fungicides and compared with thiophanate-methyl

\begin{tabular}{|c|c|c|c|c|c|c|}
\hline \multirow[b]{3}{*}{ Turf } & \multirow[b]{3}{*}{ Thiophanate-methyly } & \multirow[b]{3}{*}{ No. of isolates } & \multicolumn{4}{|c|}{ Relative growth $^{\mathrm{x}}$} \\
\hline & & & \multicolumn{2}{|c|}{ Iprodione } & \multicolumn{2}{|c|}{ Propiconazole } \\
\hline & & & Mean & Range & Mean & Range \\
\hline \multirow[t]{2}{*}{ Fairway } & Sensitive & 89 & 0.49 & $0.23-1.06$ & 0.41 & $0.16-0.86$ \\
\hline & Resistant & 89 & 0.51 & $0.28-1.03$ & 0.70 & $0.21-0.96$ \\
\hline Comparison $(P \text { value })^{\mathrm{z}}$ & $\ldots$ & $\ldots$ & 0.0587 & & $<0.0001$ & $\ldots$ \\
\hline \multirow{2}{*}{ Putting green } & Sensitive & 25 & 0.48 & $0.25-1.05$ & 0.49 & $0.21-0.81$ \\
\hline & Resistant & 48 & 0.52 & $0.29-1.01$ & 0.70 & $0.26-0.94$ \\
\hline Comparison $(P \text { value })^{\mathrm{z}}$ & $\ldots$ & $\ldots$ & 0.0288 & $\ldots$ & $<0.0001$ & $\ldots$ \\
\hline
\end{tabular}

${ }^{\mathrm{x}}$ Relative mycelial growth was calculated after $48 \mathrm{~h}$ by dividing the mean colony diameter of $S$. homoeocarpa grown on PDA amended with iprodione ( 0.4 $\mu \mathrm{g}$ a.i. $\left.\mathrm{ml}^{-1}\right)$ or propiconazole $\left(0.01 \mu \mathrm{g}\right.$ a.i. $\left.\mathrm{ml}^{-1}\right)$ by the mean diameter of isolates grown on non-amended PDA. Range was determined from the mean relative growth of each isolate across replications.

${ }^{y} S$. homoeocarpa was set on PDA amended with $1,000 \mu \mathrm{g}$ a.i. $\mathrm{ml}^{-1}$ thiophanate-methyl and scored for the presence or absence of growth after 48 hours of incubation.

${ }^{\mathrm{z}}$ For each fungicide and management location, relative mycelial growth of isolates sensitive or resistant to thiophanate-methyl were compared using an analysis of variance. 
sensitivity on tees. It is likely that fungicide resistance selection pressures were high at these two sites when compared with courses from which individually sampled isolates were collected.

The quantitative nature of DMI sensitivity is well documented $(5,24)$. The various levels of sensitivities to propiconazole of intensively sampled populations suggest that directional selection of isolates with reduced sensitivity had occurred to various degrees in New England. Each isolate from BOS3 with reduced sensitivity to iprodione also exhibited reduced sensitivity to propiconazole and was resistant to thiophanate-methyl. On the other hand, isolates from the same population that were sensitive to iprodione were also sensitive to propiconazole and thiophanate-methyl. This observation suggests that factors not related to resistance mechanisms may influence sensitivity distributions of $S$. homoeocarpa. Because population BOS3 was located adjacent to an area that was regularly treated with fungicides, it might be suggested that the rough occasionally received fungicide when the tee was treated. However, this scenario implies that fungicide selection pressure was lower, which would, theoretically, yield normally distributed sensitivities but with a lower treated population. It is also possible that the increased number of insensitive isolates in BOS3 was caused by ingress of insensitive isolates from BOS2. Most individually sampled isolates obtained from roughs $(n=90)$ were sensitive to propimean when compared with the intensively

conazole, but three isolates with reduced sensitivity were found. This suggests that movement of individuals may occur or that resistant isolates naturally develop in small quantities in untreated turf, supporting previous observations $(20,25)$.

In general, reduced sensitivity was associated among the three fungicides for individually sampled isolates (Table 6; Fig. 5). Reduced sensitivity to iprodione or propiconazole appeared to be more common among isolates resistant to thiophanatemethyl. Development of reduced sensitivity to fungicides of different mode-ofaction classes is theorized to develop independently due to the inherent biochemical separation among target sites (5). Data from this study, however, suggest that a small portion of sensitivity among fungicide classes may be related. The clustering of individually sampled isolates with highly reduced sensitivity to iprodione relative to propiconazole sensitivity (Fig. 5) could indicate that a common mechanism facilitates or contributes to development of resistance to fungicides from diverse mode-of-action classes. Previous research has documented potential relationships in sensitivity among three unrelated fungicides (benomyl, dodine, and fenarimol) of Venturia inaequalis (Cooke) G. Winter in orchards throughout the northeastern United States (26). Mechanisms of resistance not involving the target site, such as detoxification of harmful compounds, the increased efflux or decreased influx of fungicides through fungal cells, or enhanced genetic adaptability,

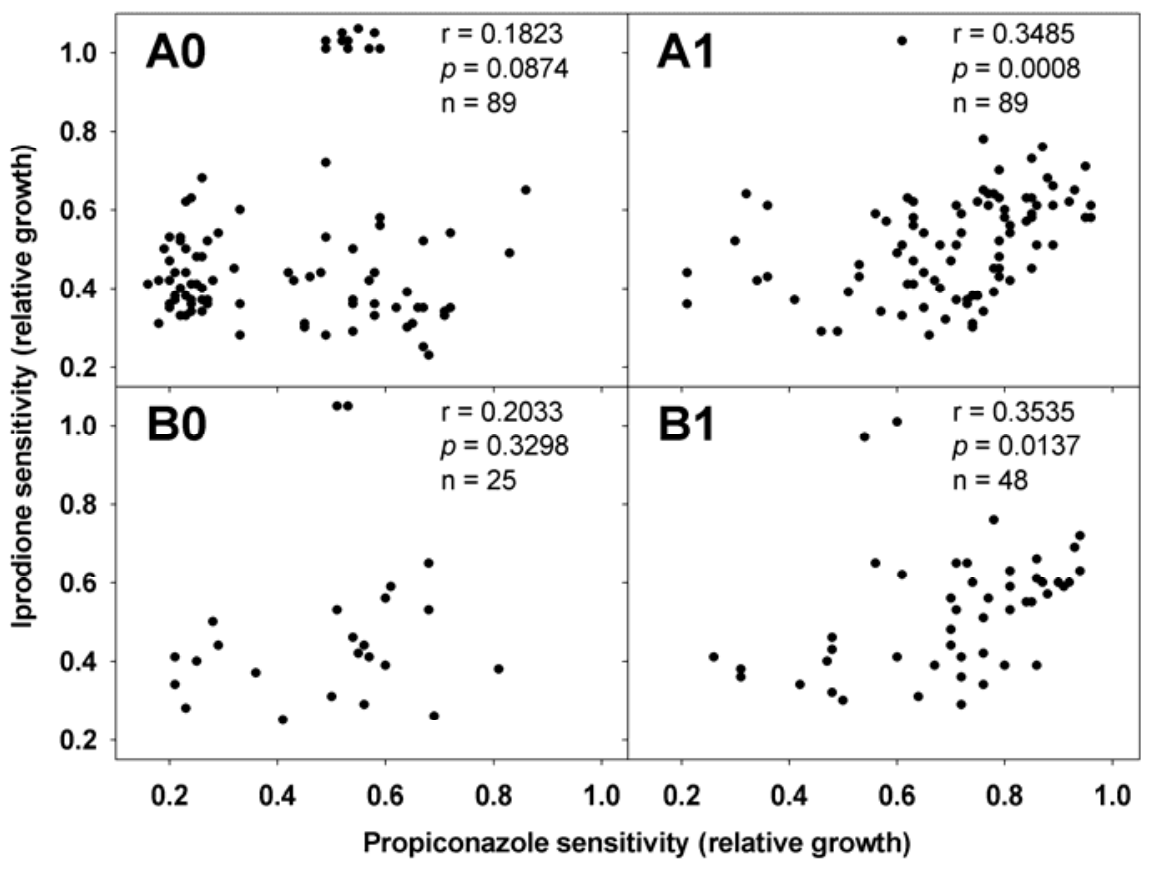

Fig. 5. Scatter plot of relative mycelial growth of individually sampled Sclerotinia homoeocarpa on potato dextrose agar amended with iprodione $\left(0.4 \mu \mathrm{g}\right.$ a.i. $\left.\mathrm{ml}^{-1}\right)$ or propiconazole $\left(0.01 \mu \mathrm{g} \mathrm{a.i.} \mathrm{ml}^{-1}\right)$. Correlations were performed on mean isolate relative mycelial growth between the fungicides for isolates obtained from A, fairways or $\mathbf{B}$, putting greens in New England and for isolates $\mathbf{0}$, sensitive or $\mathbf{1}$, resistant to thiophanate-methyl. S. homoeocarpa was grown on potato dextrose agar amended with thiophanate-methyl at $1,000 \mu \mathrm{g}$ a.i. $\mathrm{ml}^{-1}$ and scored for the presence or absence of growth. could play a role in this phenomenon $(19,24,26,38)$. Rather than being solely a biological response, it is likely that fungicide use history plays a role in simultaneous resistance to multiple fungicides. In a controlled study, however, Köller and Wilcox (26) found that fungicide sensitivity of $V$. inaequalis to both dodine and fenarimol was influenced by treatment of either fungicide alone. Little information is available about possible multiple fungicide resistance mechanisms in S. homoeocarpa.

In New England, reduced sensitivity to iprodione and propiconazole and resistance to thiophanate-methyl was present in varying degrees and influenced by management location. Although the mechanisms leading to resistance remain poorly understood, care should be taken when selecting appropriate fungicides for the control of dollar spot. The correlation of in vitro sensitivity to fungicides with field efficacy remains unclear. Data from this study, however, should serve as a baseline for existing levels of sensitivity and can be used to monitor future shifts in population sensitivities.

\section{ACKNOWLEDGMENTS}

Funding for this research was generously provided by the New England Regional Turfgrass Foundation. We thank Syngenta Crop Protection and the United States Golf Association for providing additional financial support; K. Guillard, Y.-K. Jo, R. Latin, and L. Tredway for helpful comments and isolates; and those who assisted in isolate collection.

\section{LITERATURE CITED}

1. Anonymous. 1998. Reregistration eligibility decision fact sheet: iprodione. EPA-738-F-98017. United States Environmental Protection Agency, Washington, D.C.

2. Bennett, F. T. 1937. Dollarspot disease of turf and its causal organism, Sclerotinia homoeocarpa n. sp. Ann. Appl. Biol. 24:236-257.

3. Bishop, P., Sorochan, J., Ownley, B. H., Samples, T. J., Windham, A. S., Windham, M. T., and Trigiano, R. N. 2008. Resistance of Sclerotinia homoeocarpa to iprodione, propiconazole, and thiophanate-methyl in Tennessee and northern Mississippi. Crop Sci. 48:1615-1620.

4. Bliss, C. I. 1934. The method of probits. Science 79:38-39.

5. Brent, K. J., and Hollomon, D. W. 2007. Fungicide Resistance: The Assessment of Risk, 2nd ed. FRAC Monogr. No. 2. CropLife International, Brussels.

6. Brownback, L. E., and Latin, R. 2002. Survey of isolates of Sclerotinia homoeocarpa in Indiana for sensitivity to three fungicides. (Abstr.) Phytopathology 92:S10.

7. Burpee, L. L. 1997. Control of dollar spot of creeping bentgrass caused by an isolate of Sclerotinia homoeocarpa resistant to benzimidazole and demethylation-inhibitor fungicides. Plant Dis. 81:1259-1263.

8. Cole, H., Taylor, B., and Duich, J. 1968. Evidence of differing tolerances to fungicides among isolates of Sclerotinia homoeocarpa. Phytopathology 58:683-686.

9. Conover, W. J., and Iman, R. L. 1981. Rank transformations as a bridge between parametric and nonparametric statistics. Am. Stat. 35:124-129.

10. Detweiler, A. R., Vargas, J. M., Jr., and Danneberger, T. K. 1983. Resistance of Sclero- 
tinia homoeocarpa to iprodione and benomyl. Plant Dis. 67:627-630.

11. Doney, J. C., Jr., and Vincelli, P. C. 1993. Cross resistance in Sclerotinia homoeocarpa to DMI fungicides. (Abstr.) Phytopathology 83:S54.

12. Endo, R. M. 1963. Influence of temperature on rate of growth of five fungus pathogens of turfgrass and on rate of disease spread. Phytopathology 53:857-861.

13. Faretra, F., and Pollastro, S. 1991. Genetic basis of resistance to benzimidazole and dicarboximide fungicides in Botryotinia fuckeliana (Botrytis cinerea). Mycol. Res. 95:943-951.

14. Finney, D. J. 1949. The adjustment for a natural response rate in probit analysis. Ann. Appl. Biol. 36:187-195.

15. Finney, D. J. 1964. Probit Analysis, 2nd ed. Cambridge University Press, London.

16. Goldenberg, C. W., and Cole, H. 1973. In vitro study of benomyl tolerance exhibited by Sclerotinia homoeocarpa. (Abstr.) Phytopathology 63:201.

17. Golembiewski, R. C., Vargas, J. M., Jr., Jones, A. L., and Detweiler, A. R. 1995. Detection of demethylation inhibitor (DMI) resistance in Sclerotinia homoeocarpa populations. Plant Dis. 79:491-493.

18. Grimm, C., Candolfi, M. P., and Fisch, R. 2002. A comparison of rate-response toxicity tests with Aphidius rhopalosiphi (Hymenoptera:Aphidiidae) using glass, leaves and whole plants as substrate. Chemosphere 48:581-589.

19. Hayashi, K., Schoonbeek, H.-j., Sugiura, H., and De Waard, M. A. 2001. Multidrug resistance in Botrytis cinerea associated with decreased accumulation of the azole fungicide oxpoconazole and increased transcription of the ABC transporter gene BcatrD. Pestic. Biochem. Physiol. 70:168-179.
20. Hsiang, T., Liao, A., and Benedetto, D. 2007. Sensitivity of Sclerotinia homoeocarpa to demethylation-inhibiting fungicides in Ontario, Canada, after a decade of use. Plant Pathol. 56:500-507.

21. Hsiang, T., Yang, L., and Barton, W. 1997. Baseline sensitivity and cross-resistance to demethylation-inhibiting fungicides in Ontario isolates of Sclerotinia homoeocarpa. Eur. J. Plant Pathol. 103:409-416.

22. Jo, Y.-K., Chang, S. W., Boehm, M., and Jung, G. 2008. Rapid development of fungicide resistance by Sclerotinia homoeocarpa on turfgrass. Phytopathology 98:1297-1304.

23. Jo, Y. K., Niver, A. L., Rimelspach, J. W., and Boehm, M. J. 2006. Fungicide sensitivity of Sclerotinia homoeocarpa from golf courses in Ohio. Plant Dis. 90:807-813.

24. Joseph-Horne, T., and Hollomon, D. W. 1997. Molecular mechanisms of azole resistance in fungi. FEMS Microbiol. Lett. 149:141-149.

25. Koch, P. L., Grau, C. R., Jo, Y.-K., and Jung, G. 2009. Thiophanate-methyl and propiconazole sensitivity in Sclerotinia homoeocarpa populations from golf courses in Wisconsin and Massachusetts. Plant Dis. 93:100-105.

26. Köller, W., and Wilcox, W. F. 2001. Evidence for the predisposition of fungicide-resistant isolates of Venturia inaequalis to a preferential selection for resistance to other fungicides. Phytopathology 91:776-781.

27. Massie, L. B., Cole, H., and Duich, J. 1968. Pathogen variation in relation to disease severity and control of Sclerotinia dollarspot of turfgrass by fungicides. Phytopathology 58 : 1616-1619.

28. Miller, G. L., Stevenson, K. L., and Burpee, L. L. 2002. Sensitivity of Sclerotinia homoeocarpa isolates to propiconazole and impact on control of dollar spot. Plant Dis.
86:1240-1246.

29. Mocioni, M., Gennari, M., and Gullino, M. L. 2001. Reduced sensitivity of Sclerotinia homoeocarpa to fungicides on some Italian golf courses. Int. Turfgrass Soc. Res. J. 9:701-704.

30. SAS Online Doc 9.1.3. 2002-2005. SAS Institute Inc., Cary, NC.

31. Smiley, R. W., Dernoeden, P. H., and Clarke, B. B. 2005. Compendium of Turfgrass Diseases, 3rd ed. American Phytopathological Society, St. Paul, MN.

32. Tredway, L. P 2005. Sensitivity to benzimidazole, dicarboximide, and DMI fungicides in North Carolina populations of Sclerotinia homoeocarpa. (Abstr.) Phytopathology 95:S104.

33. Vargas, J. M., Jr. 2005. Management of Turfgrass Diseases, 3rd ed. John Wiley \& Sons, Hoboken, NJ.

34. Vargas, J. M., Jr., Golembiewski, R., and Detweiler, A. R. 1992. Dollar spot resistance to DMI fungicides. Golf Course Manage. 60(3):50-54.

35. Walsh, B., Ikeda, S. S., and Boland, G. J. 1999. Biology and management of dollar spot (Sclerotinia homoeocarpa); an important disease of turfgrass. HortScience 34:13-21.

36. Warren, C. G., Sanders, P. L., and Cole, H 1974. Sclerotinia homoeocarpa tolerance to benzimidazole configuration fungicides. Phytopathology 64:1139-1142.

37. Zhou, T., and Boland, G. J. 1997. Hypovirulence and double-stranded RNA in Sclerotinia homoeocarpa. Phytopathology 87:147153.

38. Zwiers, L.-H., Stergiopoulos, I., Van Nistelrooy, J. G. M., and De Waard, M. A. 2002. ABC transporters and azole susceptibility in laboratory strains of the wheat pathogen Mycosphaerella graminicola. Antimicrob. Agents Chemother. 46:3900-3906. 